\title{
Exposure to fast-food and sweetened-drink marketing at community sports clubs
} in Australia

\author{
Jia Ying Ooia,b,c,f, John H Wiggers ${ }^{a, b, c}$, Melanie Kingsland ${ }^{a, b, c}$, \\ Christophe Lecathelinais ${ }^{a, b, c}$, Jennifer Tindalla,b,c, Tameka McFadyene, ${ }^{a, b, c}$, \\ Bosco C Rowland ${ }^{d}$, Shauna Sherkere, Allan Murphye, Rachael Heaton ${ }^{e}$, \\ Luke Wolfenden ${ }^{a, b, c}$
}

a School of Medicine and Public Health, University of Newcastle, NSW, Australia

b Hunter New England Population Health, Hunter New England Local Health District, Newcastle, NSW, Australia

c Hunter Medical Research Institute, Newcastle, NSW, Australia

' School of Psychology, Deakin University, Melbourne, VIC, Australia

e Alcohol and Drug Foundation, Melbourne, VIC, Australia

† Corresponding author: JiaYing.Ooi@health.nsw.gov.au

\section{Article history}

Publication date: December 2019

Citation: Ooi JY, Wiggers JH, Kingsland M, Lecathelinais C, Tindall J, McFadyen T, Rowland BC, Sherker S, Murphy A, Heaton R, Wolfenden L. Exposure to fastfood and sweetened-drink marketing at community sports clubs in Australia. Public Health Res Pract. 2019;29(4):e2941929. https://doi.org/10.17061/phrp2941929

\section{Background}

Most foods marketed to children and adults tend to be predominantly high in sugar and fat. ${ }^{1}$ Exposure to such marketing has been found to influence food choices and dietary patterns, particularly in children. ${ }^{2}$ Community sports clubs provide an attractive opportunity for food and beverage marketing as they provide access to large numbers of adults and children. ${ }^{3}$ Furthermore, marketing of foods and beverages in such settings may be attractive to food companies as it can foster positive product associations with sport, health and fitness. ${ }^{3}$ However, few studies have examined the exposure to unhealthy food and beverage marketing at non-elite community sports club venues. ${ }^{4}$

In a study by Kelly et al. involving telephone interviews with officials from 108 community-level children's sports clubs in Australia, sports club officials found that $17 \%$ of club sponsors were food or beverage companies. ${ }^{3}$ The study also found that nearly half of food company sponsorship arrangements were defined as unhealthy, and the most frequent marketing strategy employed as part of sponsorship arrangements was the presence of a sponsor's brand or company name or logo on players' uniforms. ${ }^{3}$ Similarly, a study of sponsorship of children's sporting clubs at national, regional and club levels in New Zealand, based on information on club websites, found that "unhealthy" sponsorship (eg for food high in fat and sugar, gambling and alcohol) was more than twice as common as "healthy" sponsorship. ${ }^{5}$ Both studies, however, relied on self-reported data. 


\section{Methods}

Given the limited observational research in this area, a cross-sectional study was undertaken in community sports clubs in New South Wales (NSW) to examine the extent of fast-food and sweetened-drink marketing and sponsorship in community sports clubs. The study was undertaken in sporting clubs for non-elite community soccer, Australian Football League (AFL), rugby league and rugby union that included both senior and junior teams and were Level 3 accredited with the national Good Sports program. Good Sports is an alcohol management accreditation program run by the Australian Drug Foundation, which aims to prevent and minimise harm caused by alcohol and other drugs. It is implemented in almost 9000 community sporting clubs across Australia, with Level 3 accreditation signalling "healthy club culture". ${ }^{6}$ As part of a larger study into alcohol management involving 188 clubs, 39 clubs were selected to participate in a separate match-day observation to examine food and beverage marketing at the club ground. The 39 clubs were located in the Hunter New England region of NSW, and were selected due to their proximity to the University of Newcastle, where this research was based.

The 1-day observation at participating clubs was undertaken by pairs of trained data collection staff on a weekend game day when junior sports teams were active, between April and May 2015. Staff recorded instances of fast-food and sweetened-drink industry marketing, defined as any visible advertisement, promotion or sponsorship in their surroundings, such as on sporting club signs, banners, equipment or uniforms. Dietitians reviewed the data and then classified fast-food sponsorship as that by outlets selling quick service, fast food (e.g. McDonald's, Kentucky Fried Chicken). Sweetened-drink sponsorship included the promotion of sugar-sweetened beverages including soft drinks, sports drinks and cordials, as defined in a previous study of community sports clubs. ${ }^{6}$ The name of the company and positioning of these advertisements were recorded. Differences between recordings of data collection staff at the same location were resolved via discussion and consensus.

\section{Findings}

Of the 39 clubs, 10 (26\%) were found to have some form of fast-food or sweetened-beverage marketing or sponsorship. These clubs had one or more recorded advertisement, promotion or sponsorship for a fast food and/or sweetened drink, as assessed by a dietitian, as follows: seven had fast food only; two had sweetened drinks only and one had both. McDonald's was the most prevalent single fast-food outlet marketed $(n=5)$. Due to the small sample size, results were analysed according to two broad groups: rugby league and rugby union were combined in one group due to their shared origins, and AFL and soccer were combined in a second group. Fast-food marketing was more common in rugby league and rugby union clubs combined ( $n=7, p=0.05$ ) compared with other types of clubs $(n=1)$, and was more common in clubs located in more regional areas $(n=6$, $p<0.01)$ compared with those in major cities $(n=2)$. There were no significant differences in the prevalence of sweetened-drink marketing by club sporting code, size or remoteness (Table 1 ).

Table 1. Food and drink marketing by club code, club size and remoteness

\begin{tabular}{|c|c|c|c|c|c|c|c|c|c|}
\hline & & Club code & & & Club size & & $\mathrm{Re}$ & loteness & \\
\hline & $\begin{array}{c}\text { AFL/ } \\
\text { soccer } \\
(n=18)^{a}\end{array}$ & $\begin{array}{l}\text { Rugby } \\
\text { league/ } \\
\text { rugby } \\
\text { union } \\
(n=21)^{\mathrm{a}}\end{array}$ & $p$ value ${ }^{b}$ & $\begin{array}{c}\leq 160 \\
\text { players }^{c} \\
(n=29)\end{array}$ & $\begin{array}{c}>160 \\
\text { players }^{c} \\
(n=9)\end{array}$ & $p$ value $^{b}$ & $\begin{array}{l}\text { Inner regional/ } \\
\text { outer regional/ } \\
\text { remote } \\
\text { Australia }^{\mathrm{d}} \\
(n=11)\end{array}$ & $\begin{array}{l}\text { Major } \\
\text { cities }^{d} \\
(n=28)\end{array}$ & $p$ value $^{b}$ \\
\hline $\begin{array}{l}\text { Fast-food } \\
\text { marketing }\end{array}$ & $\begin{array}{c}1 \\
(5.6 \%)\end{array}$ & $\begin{array}{c}7 \\
(33.3 \%)\end{array}$ & 0.05 & $\begin{array}{c}7 \\
(24.1 \%)\end{array}$ & $\begin{array}{c}1 \\
(11.1 \%)\end{array}$ & 0.65 & $\begin{array}{c}6 \\
(54.6 \%)\end{array}$ & $\begin{array}{c}2 \\
(7.1 \%)\end{array}$ & $<0.01$ \\
\hline $\begin{array}{l}\text { Sweetened- } \\
\text { drink } \\
\text { marketing }\end{array}$ & $\begin{array}{c}2 \\
(11.1 \%)\end{array}$ & $\begin{array}{c}1 \\
(4.8 \%)\end{array}$ & 0.59 & $\begin{array}{c}2 \\
(6.9 \%)\end{array}$ & $\begin{array}{c}1 \\
(11.1 \%)\end{array}$ & 1.00 & $\begin{array}{c}2 \\
(18.2 \%)\end{array}$ & $\begin{array}{c}1 \\
(3.6 \%)\end{array}$ & 0.19 \\
\hline $\begin{array}{l}\text { Fast-food or } \\
\text { sweetened- } \\
\text { drink } \\
\text { marketing }\end{array}$ & $\begin{array}{c}3 \\
(16.7 \%)\end{array}$ & $\begin{array}{c}7 \\
(33.3 \%)\end{array}$ & 0.29 & $\begin{array}{c}8 \\
(27.6 \%)\end{array}$ & $\begin{array}{c}2 \\
(22.2 \%)\end{array}$ & 1.00 & $\begin{array}{c}7 \\
(63.6 \%)\end{array}$ & $\begin{array}{c}3 \\
(10.7 \%)\end{array}$ & $<0.01$ \\
\hline
\end{tabular}

\footnotetext{
AFL clubs, $n=1$; soccer clubs, $n=17$; rugby league clubs, $n=14$; rugby union clubs, $n=7$.

b Fisher's exact test, $p \leq 0.05(95 \% \mathrm{Cl})$ is considered statistically significant.

c A figure of 160 players was chosen to separate clubs into sizes, as it is the baseline median. One club did not report club size.

d Based on the Accessibility/Remoteness Index of Australia score 34, using the Australian Standard Geographical Classification.
} 
In terms of positioning, fast-food companies advertisements were most commonly found on players' jerseys and players' accessories $(n=10)$, whereas banners were the most popular position for sweeteneddrink companies' advertisements $(n=2)$.

\section{Discussion}

Despite the small study sample, the findings provide objective data regarding the marketing of fast foods and sweetened drink at community sporting clubs. The findings suggest that food and beverage marketing in this setting is common, particularly in regional sporting clubs. The study sought to identify fast-food and sweeteneddrink advertisements, promotions or sponsorships that were visible during attendance at sporting club grounds (e.g. banners, equipment or signage on player uniforms). The prevalence of sponsorship and associated marketing strategies may be higher, had a broader range of sponsorship and marketing activities, such as website and newsletter product or brand promotions, been considered. ${ }^{3}$ Given the potential for such marketing to promote unhealthy dietary habits and contribute to excessive energy intake, efforts to reduce its prevalence may represent a useful strategy to improve public health nutrition. However, doing so may represent a considerable challenge, given community sporting clubs reliance on sponsorship revenue to ensure club viability. ${ }^{8}$

Policy makers and public health practitioners should prioritise efforts to replace community sporting club sponsorship involving companies that promote behaviours that are not in the interests of child health. This has been shown to be achievable, with randomised trials demonstrating that interventions that create more health-promoting environments and include a focus on sourcing nonalcohol-related sponsorship do not have an adverse effect on club revenue and may increase club viability by increasing spectator numbers. ${ }^{9}$ The provision of tools for clubs to develop healthy sponsorship policies, and monetary incentives to support clubs

to phase out unhealthy food sponsorship and attract alternate sponsorship opportunities have also been recommended. ${ }^{10}$ Such options should be considered by policy makers interested in promoting health in children and young people.

\section{Acknowledgements}

This paper has been supported by grants from the NSW Cancer Council and Australian Research Council as well as in-kind support from the Alcohol and Drug Foundation and Hunter New England Population Health.

\section{Peer review and provenance}

Externally peer reviewed, not commissioned.

\section{Competing interests}

None declared.

\section{Author contributions}

JYO and LW contributed to the manuscript writing. JW provided funding for the study. LW, MK, JT and TM managed and implemented the study. BR and CL provided statistical input. SS, $\mathrm{AL}$ and $\mathrm{RH}$ are Australian Drug Foundation partners who helped implement the study. All authors contributed significantly to drafting and reviewing the paper.

\section{References}

1. Scully M, Wakefield M, Niven P, Chapman K, Crawford D, Pratt IS, et al. Association between food marketing exposure and adolescents' food choices and eating behaviors. Appetite. 2012;58(1);1-5.

2. Cairns G, Angus K, Hastings G, Caraher M. Systematic reviews of the evidence on the nature, extent and effects of food marketing to children. A retrospective summary. Appetite. 2013;62:209-15.

3. Kelly B, Baur LA, Bauman AE, King L, Chapman K, Smith BJ. Food and drink sponsorship of children's sport: who pays? Health Promot Int. 2010;2:188-195.

4. Carter MA, Edwards R, Signa L, Hoek J. Availability and marketing of food and beverages to children through sports settings: a systematic review. Public Health Nutr. 2013;15(8):1373-9.

5. Maher A, Wilson N, Signal L, Thomson G. Patterns of sports sponsorship by gambling, alcohol and food companies: an internet survey. BMC Public Health. 2006;6:95

6. Good Sports. Melbourne: Alcohol and Drug Foundation; 2016. [cited 2019 Nov 12]. Available from: goodsports. com.au/

7. Wolfenden L, Kingsland M, Rowland BC, Dodds P, Gillham K, Yoong SL, et al. Improving availability, promotion and purchase of fruit and vegetable and non sugar-sweetened drink products at community sporting clubs: a randomised trial. Intl J Behav Nutr Phys Act. 2015;12(1):35.

8. Wolfenden L, Kingsland M, Rowland B, Kennedy V, Gillham K, Wiggers J. Addressing alcohol use in community sports clubs: attitudes of club representatives. Aust N Z J Public Health. 2012;36(1):93-4. 
9. Wolfenden L, Kingsland M, Rowland B, Dodds P, Sidey M, Sherker S, et al. The impact of alcohol management practices on sports club membership and revenue. Health Promot J Austr. 2016;27(2):159-61.
10. Obesity Policy Coalition. The harmful impacts of unhealthy food sponsorship in children's sporting settings: the need for action. Melbourne: Obesity Policy Coalition; 2014. Copy available from authors.

\section{Copyright: (c) (1) (2)}

(C) 2019 Ooi et al. This article is licensed under the Creative Commons Attribution-NonCommercial-ShareAlike 4.0 International Licence, which allows others to redistribute, adapt and share this work non-commercially provided they attribute the work and any adapted version of it is distributed under the same Creative Commons licence terms. See: www.creativecommons.org/licenses/by-nc-sa/4.0/ 